\title{
PRODUÇÃO E QUALIDADE DE TRÊS VARIEDADES DE CANA-DE-AÇÚCAR CULTIVADAS NO NORDESTE DE MINAS GERAIS
}

\author{
Mauro Wagner de Oliveira ${ }^{1}$, Vinicius Santos Gomes da Silva ${ }^{1 *}$, Lígia Sampaio Reis ${ }^{1}$, Daniele Costa de Oliveira ${ }^{1}$, \\ José Cléber Tenório da Silva ${ }^{1}$.
}

\begin{abstract}
${ }^{1}$ Centro de Ciências Agrárias, Universidade Federal de Alagoas, BR 104 Norte, Km 85, Rio Largo, AL.
*Autor para correspondência: Vinicius Santos Gomes da Silva, vinicius.agro2008.1@gmail.com
\end{abstract}

\begin{abstract}
RESUMO - Estudou-se no ciclo de cana-planta, a área foliar, o estado nutricional, o acúmulo de nutrientes, a qualidade do caldo e a produção de açúcares das variedades de cana-de-açúcar RB867515, RB92579 e SP791011. O estudo foi conduzido em Serra dos Aimorés, localizada no vale do Mucuri, Nordeste de Minas Gerais. $O$ delineamento experimental foi o de blocos ao acaso, com quatro repetições. A avaliação da área foliar e o estado nutricional foram realizados na fase de crescimento máximo da cultura, aos sete meses após o plantio. Aos dezessete meses, quando a cana estava madura, foram avaliadas a produção de colmos industrializáveis e a qualidade do caldo. 0 maior índice área foliar foi observado na RB92579, com valor médio de 5,04. Constatouse diferença varietal quanto aos teores foliares de nutrientes, mas não houve nenhuma variedade com maior teor foliar para todos os elementos. Em relação à qualidade dos colmos verificou-se efeito varietal apenas para a produção de açúcar, uma vez que a SP791011 foi cerca de 20\% menos produtiva que a RB867515 e RB92579, que não diferiram entre si. Entretanto, devido à rusticidade da SP791011, seu vigor de rebrota e caldo de fácil industrialização, sugere-se a sua manutenção entre as variedades cultivadas, com a implementação de medidas para a melhoria de seu estado fitossanitário, uma vez que o raquitismo da soqueira pode estar comprometendo seu potencial produtivo.
\end{abstract}

Palavras-chave: estado nutricional; cana-planta; acúmulo de nutrientes.

\section{YIELD AND QUALITY OF THE JUICE FROM THREE SUGARCANE VARIETIES CROPPED ON NORTHEAST MINAS GERAIS}

\begin{abstract}
In the cane-plant cycle were studied: the leaf area, nutritional state, nutrient accumulation, quality of the broth and the sugar production of sugarcane varieties RB867515, RB92579 and SP791011. The experiment was conducted in Serra dos Aimorés, located in the Mucuri valley municipality on northeast of Minas Gerais. The randomized block experimental design was used, with three treatments and four replicates. The leaf area and nutritional state were evaluated at seven months after planting and at seventeen were evaluated production of industrializable stalks and quality of the juice. The largest leaf area was observed in RB92579, with 5.04 average value. Varietal difference was found regarding the leaf nutrient contents, but there was no variety with higher foliar contents for all elements. Regarding the quality of the stalks and sugar production varietal effect was for sugar production, once the SP791011 was about 20\% less productive than RB867515 RB92579 and did not differ from each other. However, due to the SP791011 hardiness, vigor and regrowth broth easy industrialization suggested to keep it between the cultivated varieties, but implementing steps to improve its sanitary condition, since the ratoon stunting may be compromising their potential productive.
\end{abstract}

Keywords: nutritional state, cane-plant, nutrient accumulations 


\section{INTRODUÇÃO}

A cultura da cana-de-açúcar é de grande importância socioeconômica e ambiental para o Brasil, pois emprega grande número de pessoas de diferentes classes sociais (Oliveira et al., 2007) e contribui para a mitigação dos gases do efeito estufa, devido à elevada taxa de fixação do $\mathrm{CO}_{2}$ atmosférico pela fotossíntese, por período prolongado de tempo (Almeida et al., 2008; Oliveira et al., 2012).

A cana-de-açúcar produzida nas grandes propriedades é utilizada principalmente na produção de açúcar e álcool (indústria sucroquímica), mas, nas pequenas e médias propriedades, esta cultura é também empregada na alimentação animal, tanto de ruminantes quanto de monogástricos (Caione et al., 2011; Calheiros et al., 2012), além da fabricação de rapadura, açúcar-mascavo e cachaça (Oliveira et al. 2007; Oliveira et al., 2012).

No Estado de Minas Gerais, a região da Serra dos Aimorés é uma das áreas tradicionais de produção de cana-de-açúcar, sendo contígua às outras áreas de produção de cana nos Estados da Bahia e do Espírito Santo, que somadas alcançam cerca de 100 mil hectares. A região tem alta radiação solar e temperatura propícia ao desenvolvimento e maturação da cana (Almeida et al., 2008; Oliveira et al., 2012). 0 fator climático que mais limita a produção de cana na Serra dos Aimorés é a disponibilidade hídrica devido as grandes variações anuais em volume e distribuição de chuvas. Entretanto, em anos com boa precipitação pluvial, a produtividade da cultura ultrapassa $120 \mathrm{t}$ de colmos industrializáveis, por hectare, e com produção de açúcar superior a $15.000 \mathrm{~kg}$ por hectare, igualandose às áreas de maior produtividade no Brasil (Oliveira et al., 2007; Kaneko et al., 2009; Rapassi et al., 2009; Oliveira et al., 2013).

Para que a lavoura canavieira apresente bons níveis de produtividade, quer seja cultivada nas áreas tradicionais ou nas áreas em expansão, é de grande importância que haja a seleção e alocação das diferentes variedades de acordo com os ambientes de produção, os quais envolvem aspectos relacionados à qualidade dos solos e aos níveis esperados de produtividade (Silveira et al., 2007; Oliveira et al., 2010; Oliveira et al., 2012; Silva et al., 2012).

O objetivo deste estudo foi avaliar no ciclo de cana-planta, a área foliar, o estado nutricional, o acúmulo de nutrientes, a qualidade do caldo e a produção de açúcares por três variedades de cana: RB867515, RB92579 e SP791011, cultivadas no vale do Mucuri, nordeste de Minas Gerais.

\section{MATERIAL E MÉTODOS}

0 estudo foi conduzido no município de Serra dos Aimorés ( $17^{\circ} 50^{\prime} 54^{\prime \prime} \mathrm{S}$ e $40^{\circ} 10^{\prime} 30^{\prime \prime} \mathrm{W}$ ), nordeste de Minas Gerais. Antecedendo a implantação do estudo foram coletadas amostras de solo da área experimental, nas camadas de 0 a 20 e de 20 a $40 \mathrm{~cm}$. De posse dos resultados da análise química dessas amostras de solo, avaliou-se a necessidade de aplicação de calcário e de gesso, visando elevar a saturação por bases a $60 \%$ na camada arável e, reduzir a saturação por alumínio na camada de 20 a $40 \mathrm{~cm}$, conforme referido por Oliveira et al. (2007) e Raij (2011). Após a aplicação do calcário dolomítico a área experimental foi arada e posteriormente subsolada.

Cerca de quarenta e cinco dias após a aplicação do calcário, realizou-se uma gradagem de nivelamento e sulcou-se o solo para o plantio da cana. Para a condução do estudo adotou-se 0 delineamento experimental em blocos casualizados, com três tratamentos e quatro repetições. As parcelas foram constituídas de cinco sulcos de 5,0 metros de comprimento, espaçados de 1,40 metros. A adubação química, nas doses de 60, 200 e $180 \mathrm{~kg}$ de N, $\mathrm{P}_{2} \mathrm{O}_{5}$ e $\mathrm{K}_{2} \mathrm{O}$ por hectare, respectivamente, foi aplicada manualmente no fundo do sulco de plantio. As variedades utilizadas foram as três mais plantadas na região: RB867515, RB92579 e SP791011, rústicas, muito produtivas, com maturação média a tardia e muito adaptadas à região (Oliveira et al., 2011; Oliveira et al., 2012; Silveira et al. 2007). A densidade de plantio oscilou em torno de 15 a 18 gemas por metro de sulco, gastando-se em média 12 a $15 \mathrm{t}$ de mudas por hectare, seguindo o sistema adotado na região e também referido por Oliveira et al. (2007).

$\mathrm{Na}$ fase de crescimento máximo da cana, foi avaliada a área foliar, usando-se o método proposto por Hermann e Câmara (1999), que se baseia em medidas lineares do comprimento e da largura da folha $+3 \mathrm{e}$, no número de folhas totalmente abertas e com pelo menos $20 \%$ de área verde. Na fase de crescimento máximo da cana, também foi realizada a coleta das folhas +3 , para avaliação do estado nutricional das plantas, seguindose métodos descritos por Malavolta et al. (1997), Oliveira et al. (2007) e Raij (2011). As amostragens foram realizadas nos três sulcos centrais da parcela. 0 
limbo foliar foi analisado quanto aos teores de $\mathrm{N}, \mathrm{P}, \mathrm{K}$, $\mathrm{Ca}, \mathrm{Mg}, \mathrm{B}, \mathrm{Cu}, \mathrm{Fe}, \mathrm{Mn}$ e Zn.

Dezessete meses após o plantio, ocasião em que a cana estava madura, foi realizada a colheita e avaliados os acúmulos de matéria seca e de nutrientes na parte aérea das três variedades, a produção de colmos industrializáveis e a qualidade do caldo. À semelhança da coleta da folha +3 , as amostragens foram realizadas nos três sulcos centrais da parcela.

Após a determinação da matéria fresca, uma subamostra de toda a parte aérea foi passada em picadeira de forragem e seca $65^{\circ} \mathrm{C}$ em estufa de ventilação forçada até massa constante, para posteriormente realizar a determinação da matéria seca. Essas subamostras foram passadas em moinho tipo Willey, sendo, posteriormente quantificado o teor de nutrientes nitrogênio, fósforo, potássio, cálcio e magnésio, segundo método descrito por Malavolta et al. (1997).

Outra subamostra constituída dos colmos industrializáveis foi passada em picadeira de forragem, homogeneizada, prensada e o caldo obtido avaliado quanto à qualidade, determinando-se os teores de sacarose aparente ("Pol"), sólidos solúveis ("Brix"), fibra, pureza do caldo e $\mathrm{pH}$, seguindo-se métodos descritos por Malavolta et al. (1997), Oliveira et al. (2011) e Qudsieh et al. (2002).

Os valores médios da área foliar, do estado nutricional, do acúmulo de matéria seca e de nutrientes em toda a planta, de sacarose aparente, de sólidos solúveis e pH do caldo, produção de colmos industrializáveis e sacarose foram submetidos à análise de variância e as médias comparadas pelo teste ScottKnott a 5\% de probabilidade.

\section{RESULTADOS E DISCUSSÃO}

Os resultados da análise de variância para índice de área foliar (IAF) e teores de nitrogênio, fósforo, potássio, cálcio, magnésio, zinco, ferro, manganês, cobre e boro no terço médio da folha +3 das variedades RB867515, RB92579 e SP791011 encontram-se na Tabela 1. Houve efeito varietal significativo a $1,0 \%$ para o IAF, enquanto que, para estado nutricional das plantas, constatou-se efeito de variedade para fósforo, potássio, cálcio, magnésio, ferro, manganês e zinco.

Tabela 1 - Quadrados médios da análise de variância para índice de área foliar e concentração de nutrientes no limbo da folha+3 (Estado nutricional) da RB867515, RB92579 e SP791011, no ciclo de cana-planta, cultivadas em Serra dos Aimorés- MG.

\begin{tabular}{|c|c|c|c|c|c|c|}
\hline \multirow{2}{*}{$\begin{array}{l}\text { Fonte de } \\
\text { variação }\end{array}$} & IAF & $\mathrm{N}$ & $\mathbf{P}$ & K & $\mathrm{Ca}$ & $\mathrm{Mg}$ \\
\hline & \multicolumn{6}{|c|}{ 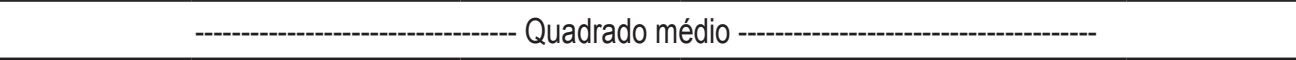 } \\
\hline Variedade & $2,0147^{* *}$ & $2,6815 \mathrm{~ns}$ & $0,1667^{*}$ & $4,9815^{*}$ & $6,9345^{\star *}$ & $0,7535^{\star * *}$ \\
\hline \multicolumn{7}{|c|}{$m^{2} m^{-2}$} \\
\hline Média Geral & 4,29 & 17,95 & 2,45 & 10,49 & 3,11 & 1,78 \\
\hline C. V. $(\%)$ & 7,12 & 13,54 & 7,27 & 7,96 & 19,33 & 7,52 \\
\hline $\begin{array}{l}\text { Fonte de } \\
\text { variação }\end{array}$ & B & $\mathrm{Cu}$ & $\mathrm{Fe}$ & Mn & $\mathrm{Zn}$ & \\
\hline & \multicolumn{6}{|c|}{-- Quadrado médio -a- } \\
\hline Variedade & $1,1124 n s$ & $0,1353 \mathrm{~ns}$ & $443,3108^{*}$ & $82,6770^{* *}$ & $29,0953^{* *}$ & \\
\hline \multicolumn{7}{|c|}{ - $\mathrm{mg} \mathrm{kg}^{-1}$} \\
\hline Média Geral & 7,86 & 1,50 & 63,52 & 16,10 & 13,95 & \\
\hline C. V. (\%) & 6,51 & 17,10 & 13,29 & 15,19 & 10,71 & \\
\hline
\end{tabular}

ns, ${ }^{* * *},{ }^{* *} e^{*}$ : não significativo e, significativo a 0,$1 ; 1,0$ e $5,0 \%$, respectivamente, pelo teste $F$.

De modo geral os coeficientes de variação para 0 índice de área foliar da cana na fase de crescimento máximo são inferiores a 10\% (Almeida et al., 2008; Oliveira et al., 2011; Silva, 2007; Silva et al., 2012), o que também foi constatado no presente estudo.
Coeficientes de variação superiores a $10 \%$ foram observados para os teores foliares de N, Ca, Cu, Mn e Zn. Oliveira et al. (2011), em estudos conduzidos em Boca da Mata - AL, em talhões de cana visualmente muito uniformes quanto ao desenvolvimento 
vegetativo, relata que os maiores coeficientes de variações nos teores foliares foram para 0 cálcio $(44,11 \%)$, seguidos do manganês $(23,51 \%)$, cobre $(23,00 \%)$ e ferro $(22,90)$.

As plantas têm capacidade para compensar pequenas variações na aquisição de nutrientes, estocando nutrientes no vacúolo (Malavolta et al., 1997; Raij, 2011), mas pelos resultados obtidos podese especular que houve grande variação desses nutrientes no solo ou diferenças entre os nutrientes quanto a homeostase. Entretanto, geralmente a maior variabilidade de nutrientes no solo é a do fósforo, que se difunde a taxas muito pequenas no solo (Demattê,
2005; Oliveira et al., 2007). De fato, nos estudos de Oliveira et al. (2011) em Boca da Mata - AL, verificouse que os maiores coeficientes de variação foram para o fósforo, cobre e manganês, todos com valores maiores que $90 \%$. Os coeficientes de variação para os teores de cálcio e magnésio no solo, extraídos com solução de $\mathrm{KCl} 1,0 \mathrm{molc} \mathrm{L}^{-1}$, foram da ordem de $40 \%$ (dados não apresentados).

$\mathrm{Na}$ tabela 2 estão apresentados os valores médios do IAF e dos teores foliares de fósforo, potássio, cálcio, magnésio, ferro, manganês e zinco, para os quais se constatou efeito de variedade (Tabela 1).

Tabela 2 - Média dos índices de área foliar (IAF) e dos teores foliares de fósforo, potássio, cálcio, magnésio, ferro, manganês e zinco em três variedades de cana, no ciclo de cana-planta, cultivadas em Serra dos Aimorés - MG.

\begin{tabular}{|c|c|c|c|c|c|c|c|c|}
\hline \multirow{2}{*}{ Variedade } & IAF & $\mathbf{P}$ & $\mathrm{K}$ & $\mathrm{Ca}$ & $\mathrm{Mg}$ & $\mathrm{Fe}$ & $\mathrm{Mn}$ & $\mathrm{Zn}$ \\
\hline & $\mathrm{m}^{2} / \mathrm{m}^{2}$ & \multicolumn{7}{|c|}{-- g/kg - } \\
\hline RB867515 & $4,21 \mathrm{~b}$ & $2,22 \mathrm{a}$ & $9,20 a$ & $4,63 \mathrm{~b}$ & $2,17 \mathrm{c}$ & $54 a$ & $19 \mathrm{~b}$ & $11 \mathrm{a}$ \\
\hline RB92579 & $5,03 \mathrm{c}$ & $2,52 b$ & $11,08 b$ & $2,50 a$ & $1,31 \mathrm{a}$ & $62 a$ & $11 \mathrm{a}$ & $14 \mathrm{a}$ \\
\hline SP791011 & $3,62 a$ & $2,61 b$ & $11,18 b$ & $2,25 a$ & $1,87 \mathrm{~b}$ & $75 b$ & $19 \mathrm{~b}$ & $17 \mathrm{~b}$ \\
\hline
\end{tabular}

${ }^{1}$ Médias seguidas de mesma letra não diferem estatisticamente entre si pelo teste de agrupamento de Scott-Knott, a 5\% de probabilidade.

Comparativamente à RB92579, o IAF da RB867515 e da SP791011 foi, respectivamente, cerca de 16 e 25\% menor. O maior IAF da RB92579, comparativamente ao da SP791011, também foi observado por Almeida et al. (2008) em trabalhos conduzidos em Rio Largo - AL, tendo-se verificado, aos 180 após o plantio, IAF de 4,5 para a RB92579 e 4,0 para a SP791011. Oliveira et al. (2011) relatam IAF médio de 4,4 para a RB867515, na fase de crescimento máximo, em talhões com produtividade de colmos industrializáveis superior a $160 \mathrm{t} \mathrm{ha}^{-1}$. Um dos fatores responsáveis pelo maior IAF da RB92579, comparativamente as outras duas variedades é o maior número de plantas por área.

Em pesquisa também conduzida no Centro de Ciências Agrárias da Universidade Federal de Alagoas, em Rio Largo - AL, com avaliações realizadas a intervalos médios de 30 dias, Silva (2007) observou que 0 índice médio de área foliar e densidade populacional da variedade RB92579 foi, estatisticamente, sempre maior que a RB867515. No período de 130 a 370 dias após o plantio da cana, o valor médio do índice de área foliar da RB867515 e RB92579 foi, respectivamente de 2,3 e 3,0, enquanto para a densidade populacional observaram-se médias de 10 e 14 plantas $/ \mathrm{m}^{2}$. Na fase de crescimento máximo, o índice de área foliar da RB92579 alcançou valores próximos a 5,0, enquanto para a RB867515 o índice de área foliar foi de aproximadamente 4,0. Silva et al. (2012) em estudo conduzido no submédio do vale São Francisco, avaliaram a área foliar da primeira rebrota da RB92579, irrigada, e o IAF variou de 1,07 aos 180 dias após 0 corte (DAC), a 5,55 aos 332 DAC. Assim, há muita similaridade dos resultados obtidos no presente estudo com de Silva (2007); Almeida et al. (2008); Oliveira et al. (2011) e Silva et al. (2012).

Comparando-se os teores de nutrientes das folhas +3 das três variedades, com os relatados por Orlando Filho (1983), Raij et al. (2011) e Malavolta et al. (1997), constata-se que a RB867515 e a RB92579 quase atingiram 0 nível de suficiência para $0 \mathrm{~N}$, enquanto para o potássio, a RB867515 apresentou pequena deficiência. Por outro lado, a SP791011 tinha teores foliares adequados para N, P, K, Ca e Mg. Nas figuras 1 e 2 pode-se observar os valores médios dos teores foliares de macro e micronutrientes das três variedades, comparativamente ao mínimo e máximo citados por Orlando Filho (1983), Malavolta et al. (1997), Oliveira et al. (2007) e Raij et al. (2011). 
Figura 1 - Teores foliares de macronutrientes em três variedades de cana, no ciclo de cana-planta, cultivadas em Serra dos Aimorés - MG, comparativamente aos valores de referência (teores mínimo e máximo) citados na literatura brasileira (Orlando Filho, 1983; Malavolta et al., 1997; Oliveira et al., 2007 e Raij et al., 2011).

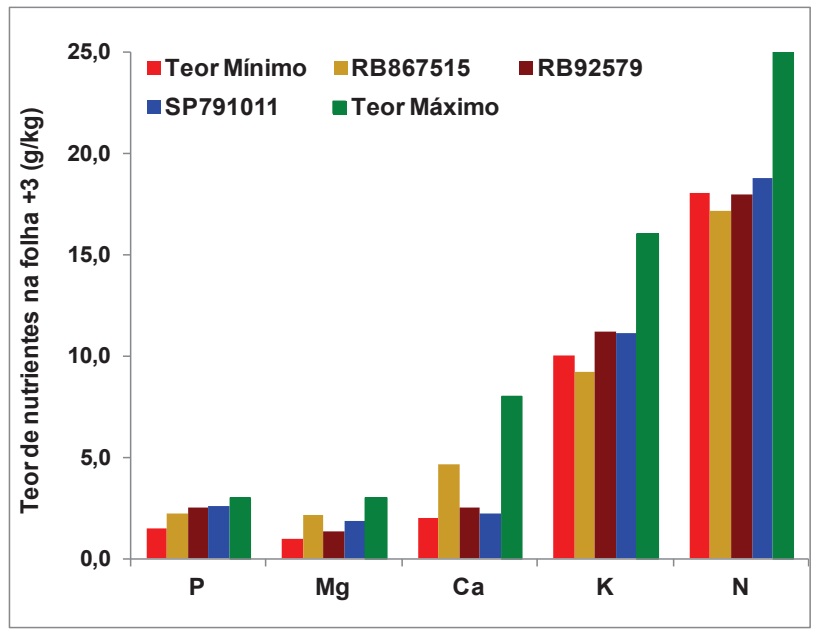

Figura 2 - Teores foliares de micronutrientes em três variedades de cana, no ciclo de cana-planta, cultivadas em Serra dos Aimorés - MG, comparativamente aos valores de referência (teores mínimo e máximo) citados na literatura brasileira (Orlando Filho, 1983; Malavolta et al., 1997; Oliveira et al., 2007 e Raij et al., 2011).

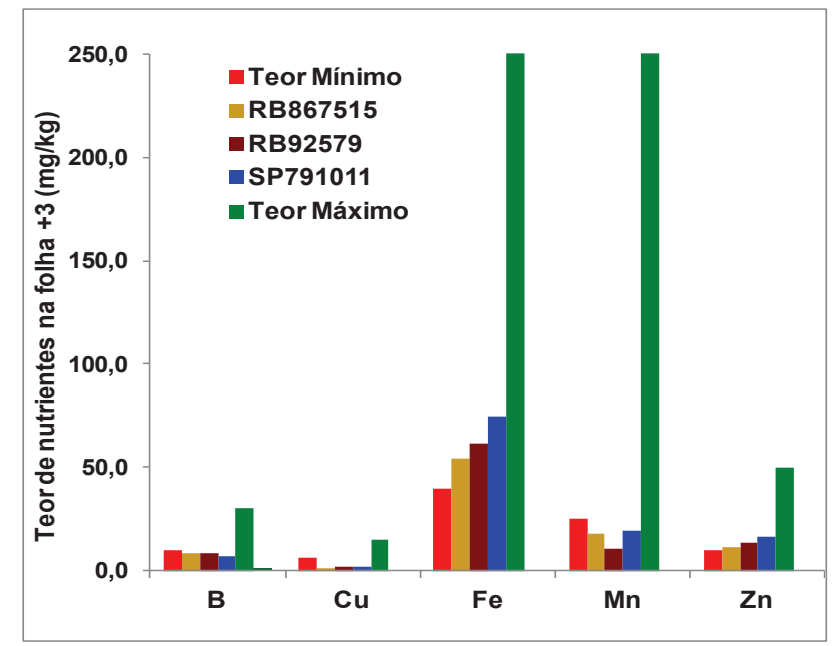

Em relação aos micronutrientes as concentrações foliares de B, Cu e Mn situaram-se abaixo do mínimo, que são, respectivamente, 10, 6 e $25 \mathrm{mg} \mathrm{kg}^{-1}$, segundo autores brasileiros (Orlando Filho,1983; Raij et al.,2011; Malavolta et al., 1997 e, Oliveira et al., 2007). Para o boro e cobre não houve efeito varietal e o valor médio foi, respectivamente, de 7,8 e $1,5 \mathrm{mg} \mathrm{kg}^{-1}$. O efeito varietal sobre a concentração foliar de $\mathrm{Mn}$ foi significativo a $1,0 \%$, tendo a RB92579 apresentado concentração média de $11 \mathrm{mg} \mathrm{kg}{ }^{-1}$, enquanto para a RB867515 e SP791011 esse teor foi de $19 \mathrm{mg} \mathrm{kg}^{-1}$. Assim, nesse ambiente edafoclimático a RB92579 teve cerca de metade da concentração foliar de Mn da RB867515 e SP791011. Contudo, o cobre constituiu a maior limitação nutricional, uma vez que o valor médio dos teores foliares desse nutriente, nas três variedades de cana, $1,50 \mathrm{mg} \mathrm{kg}^{-1}$, foi quatro vezes menor que 0 mínimo. A constatação de grande deficiência de cobre reforça os resultados obtidos em estudos conduzidos no Centro de Ciências Agrárias da Universidade Federal de Alagoas por Aristides et al. (2009). Em pesquisas conduzidas por Oliveira et al. (2011) em diversas lavouras de cana de açúcar do Estado de Alagoas, observou-se que os teores foliares de cobre e manganês estavam em concentração inferior ao valor mínimo citados por Malavolta et al. (1997) e Oliveira et al. (2007).

Das 10 variáveis relacionadas à qualidade do caldo, à produção de açúcar e ao acúmulo de macronutrientes na biomassa da parte aérea das três variedades de cana, houve efeito significativo apenas para a fibra dos colmos industrializáveis e a produção de açúcares (Tabela 3). 0 coeficiente de variação para as variáveis relacionadas à qualidade do caldo: $\mathrm{pH}$ do caldo, sólidos solúveis (Brix), sacarose aparente no caldo (Pol do caldo), pureza do caldo e, fibra dos colmos foi inferior a 4,0\%, ressaltando que a ausência de efeito varietal para essas variáveis não se deveu a dispersão dos resultados.

Os valores de $\mathrm{pH}$ do caldo foram de 5,61, característicos de caldo sem deterioração microbiana. 0 tempo médio entre o corte da cana não despalhada a fogo e a extração do caldo foi inferior a oito horas. Yusof et al. (2000), em estudo conduzido na Malásia, avaliaram as modificações na qualidade da cana devido a estocagem e atraso na extração do caldo e constaram que o pH do caldo da cana recém colhida era de 5,7. Entretanto, quando os colmos foram estocados a $27{ }^{\circ} \mathrm{C}$ houve redução do $\mathrm{pH}$ : aos quatro dias para 5,5 e, aos 10 dias para pH 5,0. Eggleston (2002), em estudos conduzidos em condições de laboratório, na Lousiânia (E.UA.), verificaram que a diminuição do $\mathrm{pH}$ do caldo ocorria a partir de 12 horas após a extração: imediatamente após a extração, o pH do caldo era 5,3, decrescendo para 4,7, doze horas após e atingindo $\mathrm{pH} 3,1$ quarenta horas após a extração. 
Tabela 3 - Quadrados médios da análise de variância para pH do caldo, sólidos solúveis (Brix), sacarose aparente no caldo (Pol do caldo), pureza do caldo, fibra dos colmos, produção de colmos industrializáveis, produção de açúcares e acúmulos de nitrogênio, fósforo e potássio na biomassa da parte aérea da RB867515, RB92579 e SP791011, no ciclo de cana-planta, cultivadas em Serra dos Aimorés- MG.

\begin{tabular}{|c|c|c|c|c|c|}
\hline Fonte de variação & $\mathrm{pH}$ & Sólidos Solúveis & $\begin{array}{l}\text { Sacarose } \\
\text { Aparente }\end{array}$ & Pureza do caldo & Fibra \\
\hline & \multicolumn{5}{|c|}{ Quadrado médio - - - } \\
\hline Variedade & $0,02583 n s$ & $0,6723 n s$ & $0,7092 n s$ & $0,8640 \mathrm{~ns}$ & $4,27^{* * *}$ \\
\hline \multicolumn{6}{|c|}{ 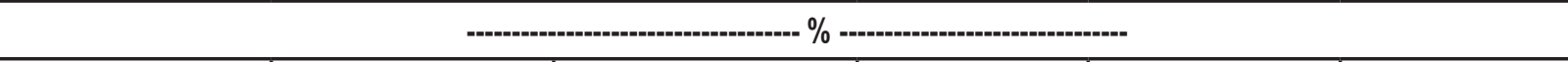 } \\
\hline Média Geral & 5,61 & 21,22 & 18,42 & 86,90 & 12,00 \\
\hline C. V. $(\%)$ & 2,67 & 3,33 & 2,94 & 3,63 & 3,24 \\
\hline \multirow[t]{2}{*}{ Fonte de variação } & $\begin{array}{c}\text { Produção de } \\
\text { colmos }\end{array}$ & Produção de açúcar & Acúmulo de $\mathrm{N}$ & Acúmulo de $P$ & Acúmulo de $\mathrm{K}$ \\
\hline & \multicolumn{5}{|c|}{ - Quadrado médio - } \\
\hline \multirow[t]{2}{*}{ Variedade } & $230,78 \mathrm{~ns}$ & $157,66^{* *}$ & $534,27 \mathrm{~ns}$ & $55,53 \mathrm{~ns}$ & $153,08 \mathrm{~ns}$ \\
\hline & \multicolumn{5}{|c|}{ - } \\
\hline Média Geral & 128,82 & 17,19 & 107,14 & 37,58 & 221,96 \\
\hline C. V. $(\%)$ & 6,73 & 7,09 & 15,95 & 12,32 & 9,35 \\
\hline
\end{tabular}

ns, ${ }^{* * *},{ }^{* *} e^{*}$ : não significativo e, significativo a 0,$1 ; 1,0$ e $5,0 \%$, respectivamente, pelo teste $F$.

As concentrações de sólidos solúveis, sacarose aparente no caldo e pureza situaram-se próximas às citadas por Fernandes (2000); Barbosa et al. (2002), Oliveira et al (2011). Nos estudos conduzidos por Oliveira et al. (2011) em Boca da Mata - AL, a fibra dos colmos da RB867515 foi em média de 12,2\% e, com teores de sólidos solúveis, sacarose aparente no caldo e pureza, respectivamente de 20,$2 ; 16,5$ e $82,5 \%$. Assim, pode-se inferir que as variedades estavam maduras e 0 caldo tinha bons teores de açúcares. A produção média de colmos industrializáveis foi alta, cerca de 130 t/ha, valores próximos aos citados por Oliveira et al. (2012), em estudos conduzidos em Iturama - Triângulo Mineiro e, Kaneko et al. (2009) e Rapassi et al. (2009), no oeste de São Paulo. Em trabalhos conduzidos em Viçosa-MG, em solos com baixo teor de $P$ e média saturação por bases, Silveira et al. (2002) avaliaram o crescimento e a produção de sacarose por seis variedades de cana e verificaram que a RB867515 destacou-se pela produção de açúcar, alcançando produtividade de 16,6 toneladas por hectare.

0 percentual de fibra das três variedades apresentou efeito significativo a $0,1 \%$. 0 menor percentual foi o da RB92579 com valor médio de 10,91, a seguir a RB867515 com 12,12\% de fibra e, por último a SP791011 com 12,97\%. Em relação à produção de açúcares, o efeito varietal foi significativo a 1,0\%, tendo a SP791011 apresentado a menor produção: 15,06 t ha-1. A produção de açúcar da RB867515 e da RB92579 foi estatisticamente semelhante, com valores médios, respectivamente de 17,51 e 19,00 $\mathrm{t}$ ha $^{-1}$. Possivelmente 0 estado fitossanitário da SP791011, especialmente o raquitismo da soqueira, esteja comprometendo o potencial produtivo dessa variedade. Ponte et al. (2010) em levantamento realizado na região de Serra dos Aimorés, constatou que $34,20 \%$ dos colmos da SP791011 foram soropositivos para a presença da bactéria Leifsonia xyli subsp xyli, causadora do raquitismo da soqueira Ainda segundo Ponte et al. (2010) uma das limitações das pesquisas com raquitismo-da-soqueira da cana-de-açucar é a necessidade de método de diagnóstico da doença, uma vez que seus sintomas são inespecíficos, os quais podem ser evidenciados em algumas variedades suscetíveis somente em épocas com déficit hídrico. Pelo fato da doença não apresentar sintomas aparentes, os produtores não percebem a necessidade de controle do raquitismo. $O$ diagnóstico do raquitismo requer a detecção da bactéria causadora da doença em amostras de seiva do xilema, extraídas de internódios basais de colmos amostrados no campo, utilizando-se para isso técnicas sorológicas. 
Tabela 4. Teste de média para fibra e produção de açúcar da RB867515, RB92579 e SP791011, no ciclo de cana-planta, cultivadas em Serra dos Aimorés - MG.

\begin{tabular}{ccc}
\cline { 2 - 3 } Variedade & Fibra & TPH \\
& tha $^{-1}$ \\
\hline RB867515 & $12,12 \mathrm{~b}$ & $17,51 \mathrm{~b}$ \\
RB92579 & $10,91 \mathrm{a}$ & $19,00 \mathrm{~b}$ \\
SP791011 & $12,97 \mathrm{c}$ & $15,06 \mathrm{a}$ \\
\hline
\end{tabular}

${ }^{1}$ Médias seguidas de mesma letra não diferem estatisticamente entre si pelo teste de Scott-Knott, a 5\% de probabilidade.

Os acúmulo de nitrogênio, fósforo e potássio na biomassa da parte aérea também foram de mesma ordem de grandeza dos citados por Orlando Filho (1983), Oliveira et al. (2007) e Calheiros et al. (2012), que relatam acúmulo de N, P eK da ordem de 150, 40, 180 para uma produção de cerca de $100 \mathrm{t}$ de colmos industrializáveis.

Desse modo pode-se concluir que o maior índice de área foliar foi observado na RB92579, em relação ao estado nutricional embora houvesse diferença varietal quanto aos teores foliares de nutrientes, nenhuma variedade apresentou generalizadamente maior concentração foliar para todos os nutrientes. No que se refere à produção de açúcares, o efeito varietal foi significativo a $1,0 \%$, sendo a produção de açúcar da RB867515 e da RB92579 semelhante, com valores médios, respectivamente de 17,51 e 19,00 t ha-1, enquanto a SP791011 produziu 15,06 t ha-1.

\section{REFERÊNCIAS BIBLIOGRÁFICAS}

ALMEIDA, A. C. S.; SOUZA, J. L.; TEODORO, I.; BARBOSA, G. V. S.; MOURA FILHO, G.; FERREIRA JÚNIOR, R. A. Desenvolvimento vegetativo e produção de variedades de cana-de-açúcar em relação à disponibilidade hídrica e unidades térmicas. Ciência e Agrotecnologia. 2008, 32, 1441-1448.

ARISTIDES, E. V. S.; FERRO, J. H. A.; OLIVEIRA, M. W.; OLIVEIRA, T. B. A.; PAULINO, A. S. Qualidade do caldo de duas variedades de cana adubadas com doses de cobre e manganês. In: IV Congres so de Pesquisa e Inovação da Rede Norte e Nordeste de Educação Tecnológica- Belém - PA, 2009. CD ROOM

BARBOSA, M. H. P.; OLIVEIRA, M. W.; SILVEIRA, L. C. I., DAMASCENO, C. M.; MENDES, L. C. Acúmulo e alocação de nutrientes pela RB72454 no ciclo da cana-planta. Anais do 8 Congresso Nacional da STAB. Pernambuco, 2002, 234-238.
CAIONE, G.; LANGE, A.; BENETTI, C.G.S.; FERNANDES, F. M. Fontes de fósforo para a adubação de cana-de-açúcar forrageira no cerrado. Pesquisa Agropecuária Tropical. 2011, 41, 66-73.

CALHEIROS, A. S.; OLIVEIRA, M. W.; FERREIRA, V. M.; BARBOSA, G. V. S.; SANTIAGO, A. D.;ARISTIDES, E.V.S. Produção de biomassa, de açúcar e de proteína em função de variedades de cana e de adubação fosfatada. Semina: Ciências Agrárias. 2012, 33, 809818.

DEMATTÊ, J. L. I. Recuperação e manutenção da fertilidade dos solos. Informações Agronômicas. 2005, $111,1-24$.

EGGLESTON, G. Deterioration of cane juice -sources and indicators. Food Chemistry, 2002, 78, 95-103.

FERNANDES, A. C. Cálculos na agroindústria da canade-açúcar. STAB - Sociedade das Técnicos Açúcareiro e Alcooleiros do Brasil. 2000. 193p.

HERMANN, E. R.; CÂMARA, G. M. S. Um método simples para estimar a área foliar de cana-de-açúcar. STAB. Açúcar, Álcool \& Subprodutos, 1999, 17, 3234.

KANEKO, F. H.; TARSITANO, M. A. A.; RAPASSI, R. M. A.; CHIODEROLI, C. A.; NAKAYAMA, F. T. Análise econômica da produção de cana-de-açúcar considerando-se a terceirização das operações agrícolas: o caso de um produtor rural. Pesquisa Agropecuária Tropical. 2009, 39, 266-270.

MALAVOLTA, E.; VITTI, G. C.; OLIVEIRA, S. Avaliação do estado nutricional das plantas princípios e aplicações. Piracicaba: Associação Brasileira para Pesquisa da Potassa e do Fosfato, 1997. 226 p. 
OLIVEIRA, T.B.A.; BORNIA, A. C.; OLIVEIRA, M.W. Gestão do conhecimento na produção de cana-deaçúcar. In: XIII Semana de la Ingeniería de Producción. Gramado - RS, 2013. Meio magnético.

OLIVEIRA, M. W.; FREIRE, F. M.; MACÊDO, G. A. R.; FERREIRA, J. J. Nutrição mineral e adubação da canade-açúcar. Informe Agropecuário. 2007, 28, 239, 30-43.

OLIVEIRA, M.W.; MAGRINI, J. L.; LYRA, F. E. V.; VALDUGA, G. R.; PEREIRA, M. G.; TENORIO, C. J. M. ; ARISTIDES, E. V. S. Produção da RB867515 influenciada pela aplicação de substâncias húmicas, aminoácidos e extrato de algas marinhas. STAB Açúcar, Álcool e Subprodutos, 2011, 30, 30-33.

OLIVEIRA, R.A; SANTOS, R.; RIBEIRO, A.; ZOLNIER, S.; BARBOSA, M. H. P. Estimativa da produtividade da cana-de-açúcar para as principais regiões produtoras de Minas Gerais usando o método ZAE. Rev. Bras. Eng. Agric. Ambiental. 2012a, 16, 549-557.

OLIVEIRA, T. B. A., SELIG, P. M.; BARBOSA, V. M.; CAMPOS, L. M. S.; BORNIA, A. C.; OLIVEIRA, M. W. Tecnologia e custo de produção de cana-de-açúcar: um estudo de caso em uma propriedade agrícola. Latin American Journal of Business Management. 2012b, 3 , $1,150-172$.

ORLANDO FILHO, J. Nutrição e adubação da canade-açúcar no Brasil. Instituto do Açúcar e do Álcool. Programa Nacional de Melhoramento da Cana-deAçúcar. Planalsucar. 1983. 368 p.

PONTE, E. C.; SILVEIRA, F.S; CARNEIRO JUNIOR, J. B.; LIMA, R. M. P; Incidência de Leifsonia xyli subsp. xyli em áreas de multiplicação de cana-de-açúcar no Espírito Santo, sul da Bahia e oeste de Minas Gerais. Summa phytopathol, 2010, 36, 313-321.
QUDSIEH, H. Y. M.; YOSOF, S.; OSMAN, A.; RAHMAN, R. A. Effect of maturity on chorophyll, tannin, color, and polyphenol oxidase (PPO) activity of sugarcane juice (Saccharum officinarum Var. Yellow Cane). Journal of Agricultural and Food Chemistry, 2012, 50, 16151618.

RAIJ, B. Fertilidade do solo e manejo de nutrientes. Piracicaba: International Plant Nutrition Institute, 2011. 420p.

RAPASSI, R. M.A.; TARSITANO, M. A. A.; BOLONHEZI, A. C. Avaliação técnica e econômica de sistemas de produção de cana-de-açúcar (Saccharum spp) na região oeste do Estado de São Paulo. Informações Econômicas. 2009, 39, 11-21.

SILVA, E. T. Análise de crescimento e produtividade de duas variedades de cana-de-açúcar (saccharum spp) influenciadas por doses de fósforo. Rio Largo-AL, 2007, 56p. (Dissertação de Mestrado).

SILVA, T. G. F.; MOURA, M. S. B.; ZOLNIER, S.; CARMO, J. F. A.; SOUZA, L. S. B. Biometria da parte aérea da cana irrigada no submédio do vale do São Francisco. Ciência Agronômica. 2012, 48, 500-509.

SILVEIRA, L. C. I.; BARBOSA, M. H. P.; CHAVES, J. M. P. Variedades melhoradas de cana-de-açúcar para Minas Gerais. Informe Agropecuário, 2007, 28, 25-29.

SILVEIRA, L. C. I.; OLIVEIRA, M. W.; BARBOSA, M. H .P. Crescimento e acúmulo de sacarose por seis variedades de cana. In: Congresso Nacional da Sociedade dos Técnicos Açucareiros e Alcooleiros do Brasil, 8, Recife, 2002. Anais. Recife: 2002.

YUSOF, S., SHIAN, L.S.; OSMAN, A. Changes in quality of sugarcane upon delayed extraction and storage. Food Chemistry. 2000, 68, 395-400. 